\title{
PROBLEMS OF ECONOMICS
}

\section{Assessment of the Competitive Trends in the Development of Production Business in the Main Segments of the World Steel Market}

\author{
S. V. Bogdanov* \\ State University of Management, Moscow, 109542 Russia \\ *e-mail: bsv-29@yandex.ru
}

Received March 17, 2020; revised March 31, 2020; accepted March 31, 2020

\begin{abstract}
The variants of efficiency of strategic development of competitive relations in the production and external trading areas of business are assessed in the world steel market and its segments. Reasonability of the developed proposals is demonstrated for scheduling the business activities of metallurgical manufacturers in modern economic environment.
\end{abstract}

Keywords: world steel market and its territorial segments, pure strategy of business development, statistical and integral indices, steel products

DOI: $10.1134 / \mathrm{S} 0036029521060082$

From the 1950s to date, the development of industrial economy characterized by changes of technological modes (Kondratiev cycles) has been accompanied by an increase in the production of steel as the major structural material of human civilization (Fig. 1) $[1,2]$. Herewith, the rates of change of the amount of steelmaking were different in different time periods.

In the considered 70 year time period, which is comparable with the duration of the Kondratiev cycle, the achieved increase in steel production in the world nearly by 10 times was stipulated by intensive development of aircraft engineering, spacecraft, nuclear and conventional power industry, new types of transport systems, electronics and innovative means of communication, industrial and civil construction, as well as other metal intensive industries. The mentioned transformations in the world were accompanied by changes in not only technological modes but also in the structure, the content and business activities of personnel of metallurgical enterprises, and the transnational activity of overall metallurgical business was expanded. Moreover, the main segments of the world metal market were transformed, which was stipulated by the changes in political and economic situation in the world: disintegration of block of socialist countries and the Soviet Union, establishment of independent countries, which started to enter into various economic, political, and military unions, increase in transboundary capital flows on the world market goods and services. However, despite these changes, the main segments of steel market generated according geographical principles in the 1980s in fact remained up till now. Herewith, their operational performances were seriously adjusted stipulated by actual operation of leading metallurgical companies and changes of world leaders of steel production. The existing segments of the world steel markets are presented as follows: European Union (28), other European Countries, CIS, North America, South America, Africa, Middle East, Asia, and Oceania. Each of the known segments of the world steel market is characterized by specific production subsystem closely related with the steel business on the world market of metal products.

While using the macroscopic approach to the analysis of development of complex industrial and economic system [3], it should be mentioned that these segments could be considered as system elements of the world steel market. Let us assume that the indices characterizing metal flows in these segments are the order parameters, varying in self-organizing system of the world steel market, and the relatively constant steady modes are presented by fixed amounts of monetary funds intended and transferred for production of metal products and its exchange among market counteragents. Under such assumptions, it is possible to estimate the conditions of changes in the metal flows in the industrial and foreign trading areas of market business activity. The time distribution of the average indices of transfer (movement) of metal in industrial and export/import areas would change provided that the conditions of discreteness of money payments are satisfied. If distribution fluctuations are steady (i.e., the order parameters exceed their critical values), this leads to transformation of the existing market struc- 
(a)

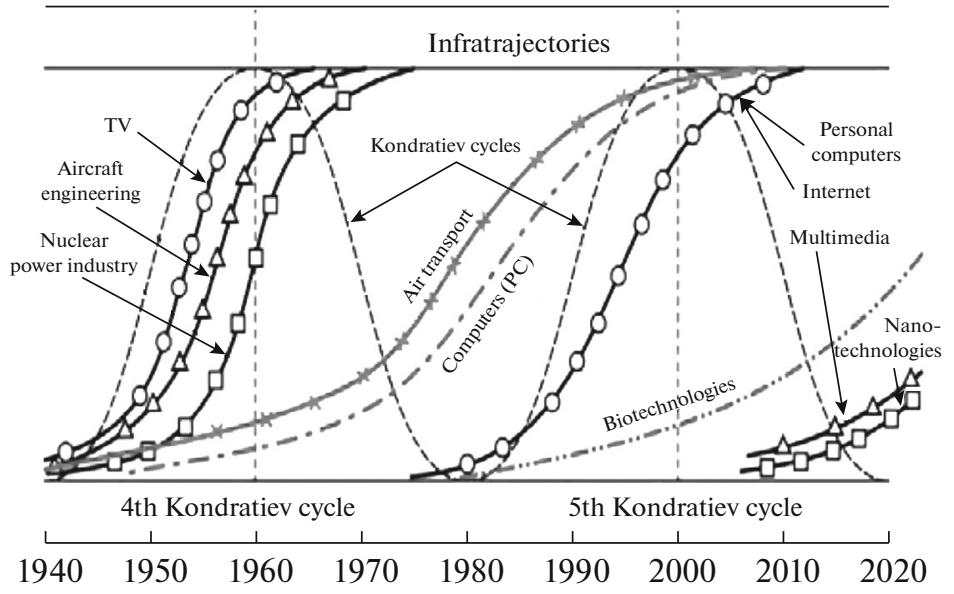

(b)

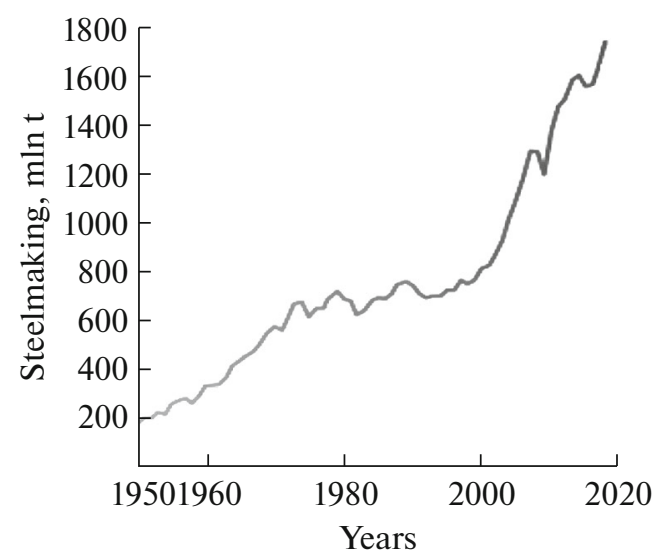

Fig. 1. Change of (a) technological modes and (b) steelmaking at the turn of the 20th and the 21st centuries [1,2].

ture of the considered industrial and business structure reflecting the business activity in the world steel market and in its territorial segments.

It is known that, near the points of unsteady development of system, the information referring to the order parameters sharply changes, whereas the information of subordinated modes is not exposed to such changes [3, p. 112]. In this work, the data on amounts of steel production and export/import operation in various segments of the modern world steel market are used as parameters characterizing control system impact on the situation on the world steel market. In the course of analysis, the opportunity of strategic development of competitive relations is estimated in industrial and foreign trading areas of business activity on the global steel market.

Figure $1 \mathrm{~b}$ illustrates the changes in the steel production in the world from 1950 to 2018 and in the turn of the 20th and the 21st centuries, when the main segments of steel market were being transformed. Three periods can be highlighted in this nearly 40 year interval, characterizing the changes in the positions of participants on the market, namely, metallurgical holdings, companies, and enterprises manufacturing metal products in the main segments of the world steel market: (1) before 1991 (period of formation and monopole positioning of the Soviet Union on the steel market), (2) 1992-2008 (period of establishment of CIS segment and strengthening of the Asian segment of steel manufactures), and (3) 2009-2018 (period of monopole positioning of China in this market and the impact of global economic crisis and stagnation on the world economy).

The irregular distribution of the data on steelmaking in these periods demonstrates the influence of production, economic, and market factors in various segments of the world market on the total amount of steelmaking. An analysis of the published data demonstrated that the formation of main segments of the steel market progressed rather dynamically nearly to the commencement of the economic crisis in South East Asia and technical default in Russia in 19971998 [4-6]. Up to 1998 various final data were presented for the European Union countries (EU10, EU12, EU15, EU25, EU27, EU28), other European countries, the Soviet Union, CIS, North and South Americas, Africa, Middle East, and Asia and Oceania (cumulative and separate variants). In fact, starting from 1998-1999, the official reports of World Steel Association (WSA) highlighted nine main segments of the world steel market [4, 5]. The statistic data for these segments are summarized in Table 1. These indices characterize the order parameters of self-organizing system. Data distribution for making, export, and import in 1998-2018 are illustrated in Fig. 2.

Figure 2 depicts the respective indices close to normal distribution, as well as displacement of maximum of their frequency distributions towards increase by $20-50$ rel $\%$ for the time periods before and after the 2008-2009 crisis. This indicates at important changes of market conditions peculiar for the state of production and export/import operations in the considered strategic time periods. The subsequent analysis of the given statistic data for the nine market segments revealed that these indices varied in sufficiently wide range. For instance, for European Union the lowest deviations equaled to -15 rel $\%$, whereas for Asia the highest deviation was up to +135 rel $\%$. Wide range of variations of the considered indices made it possible to conclude that the self regulation of the world steel production was determined by the changes in flow of steel products in the main segments of the world market. This flow was controlled by the capital movement upon satisfying demand for steel products in various segments of the world market of goods and services. 


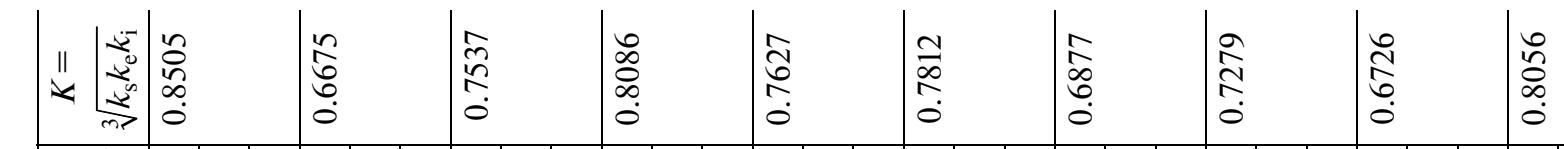

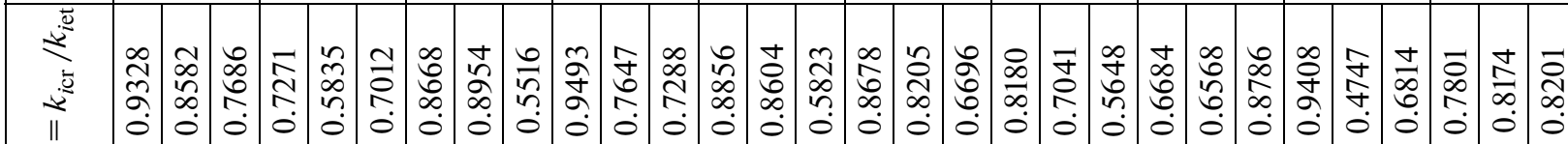

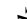

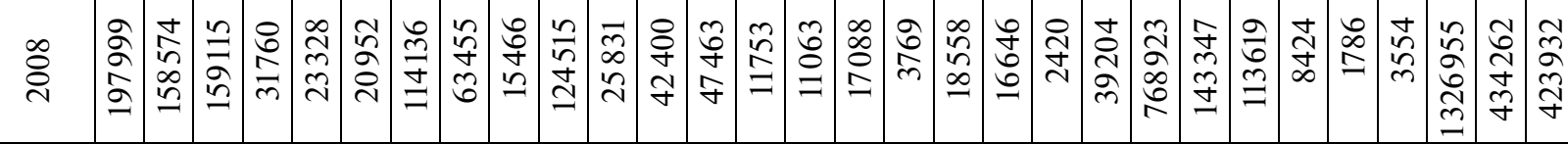

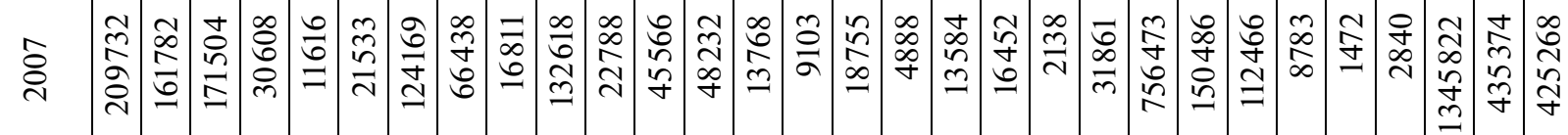

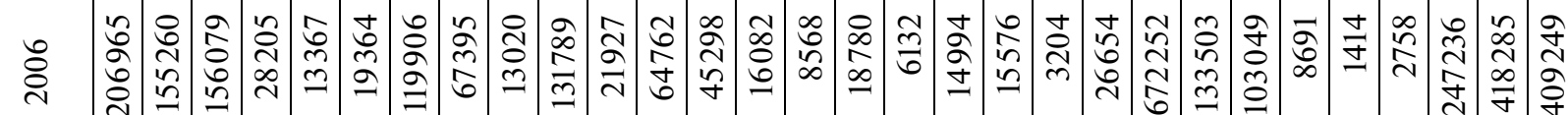

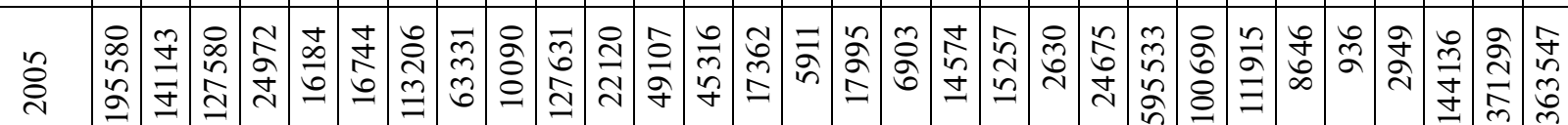

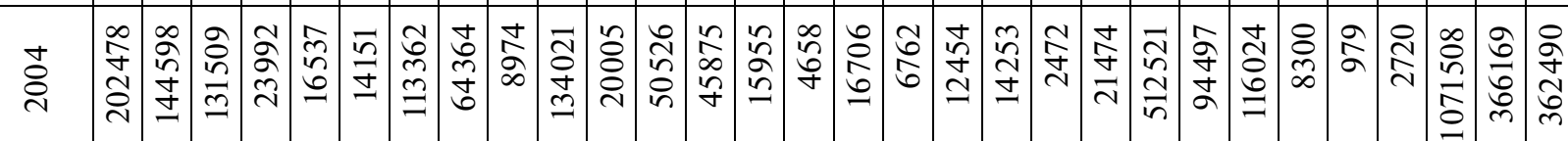
*

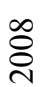

$\stackrel{9}{ \pm}$

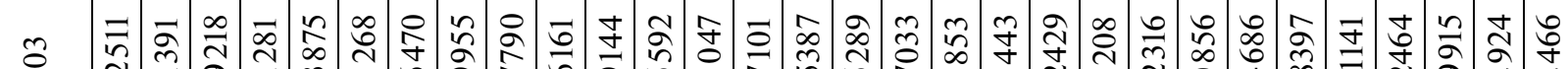

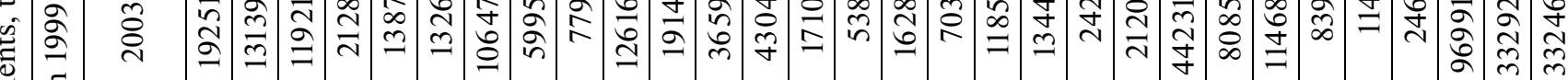
$\Xi$

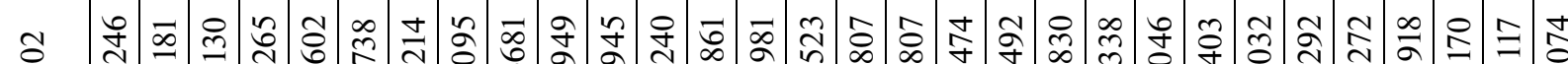

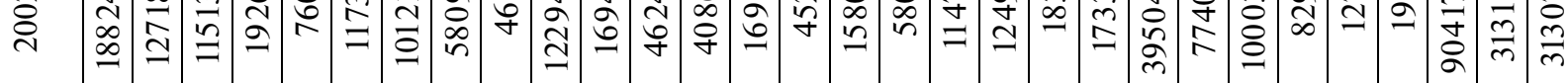

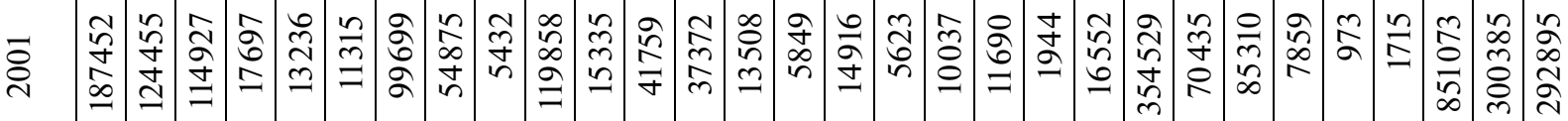

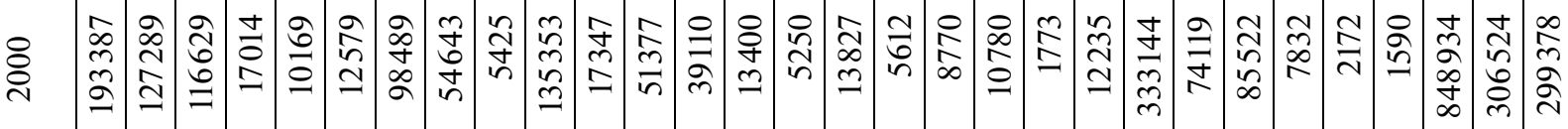

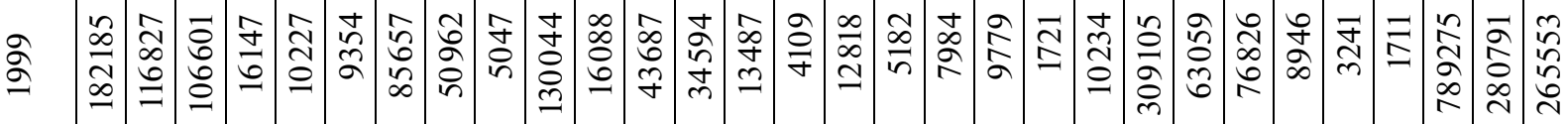

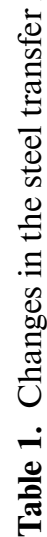

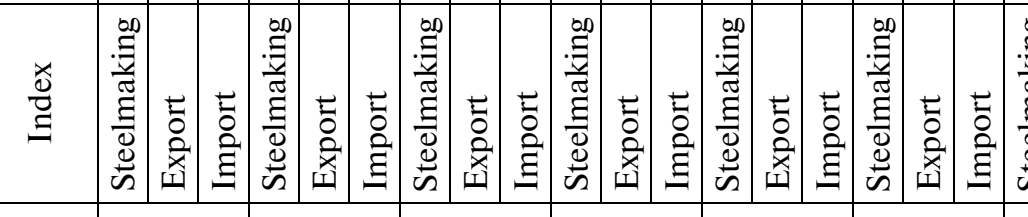

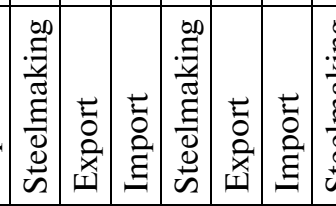

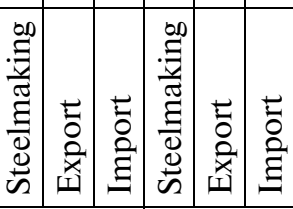

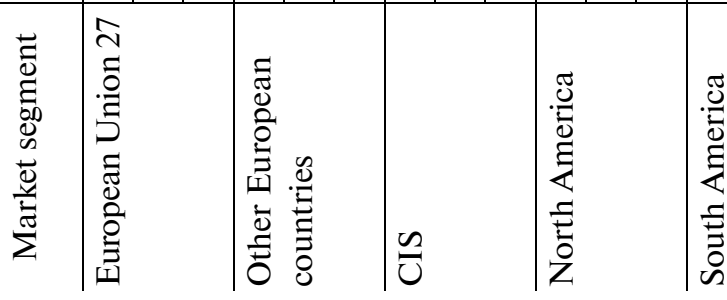
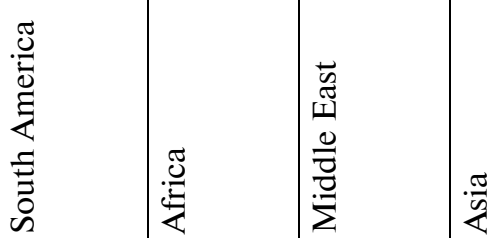


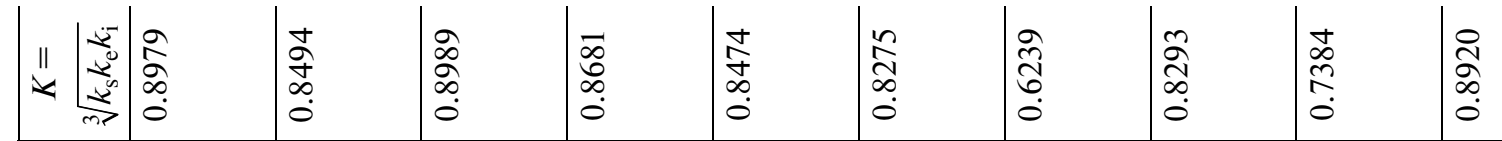

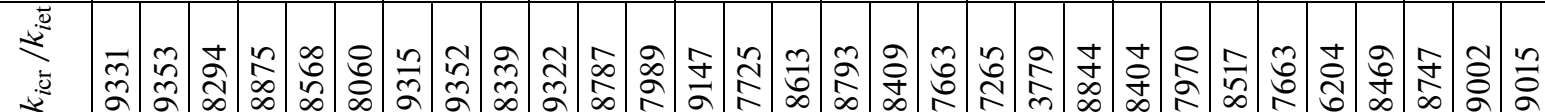

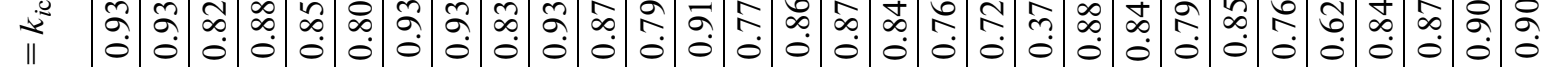

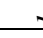

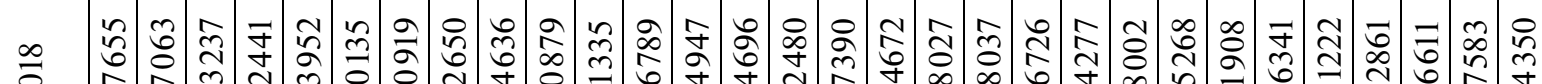

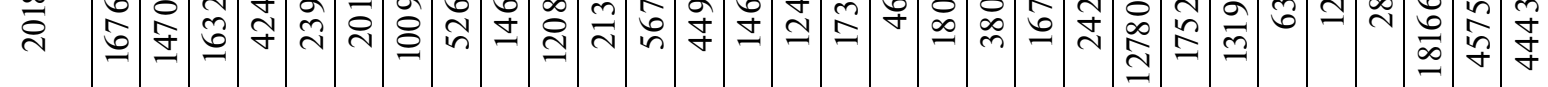

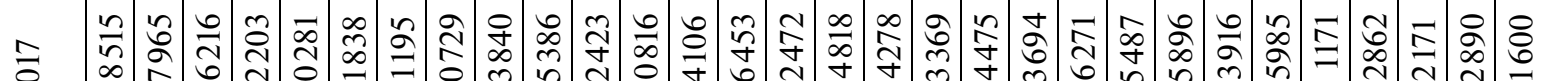

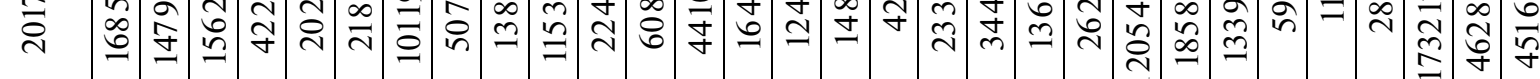

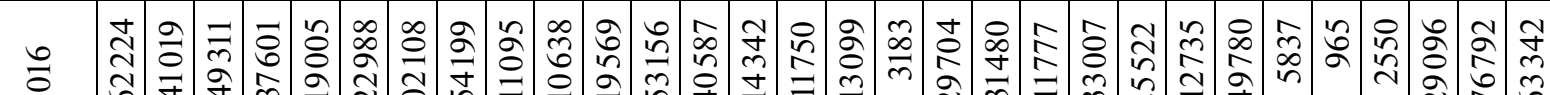

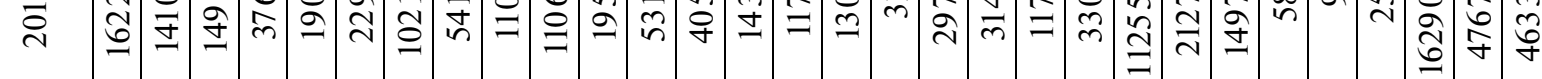

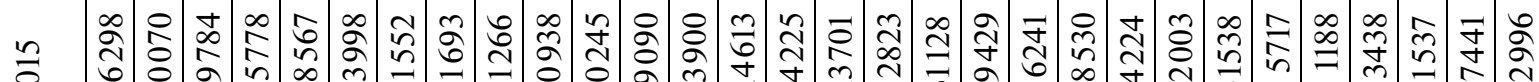

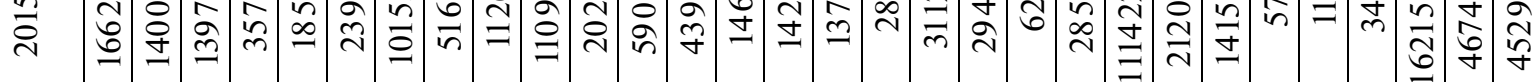

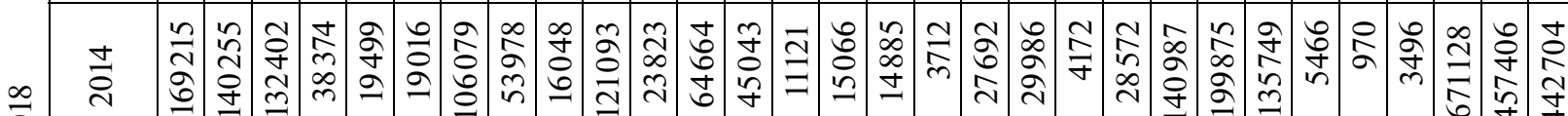

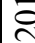

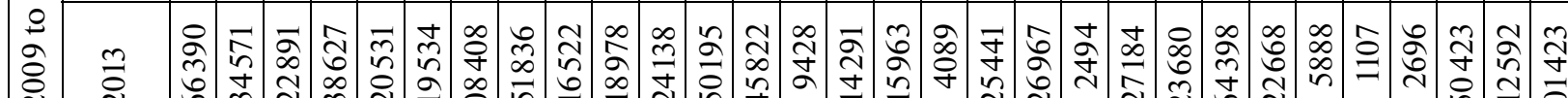

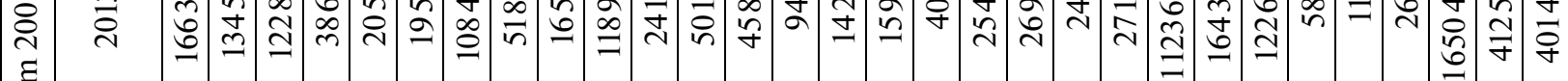
总

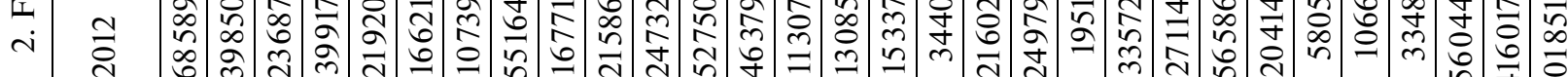
సे

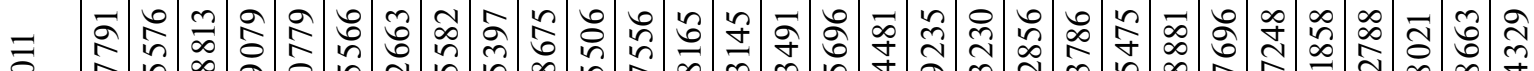

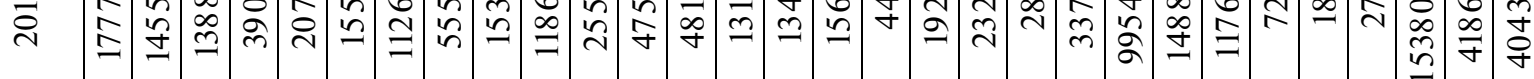

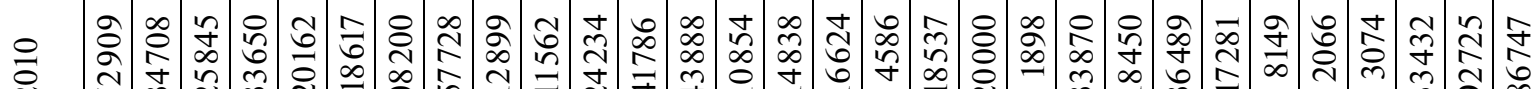

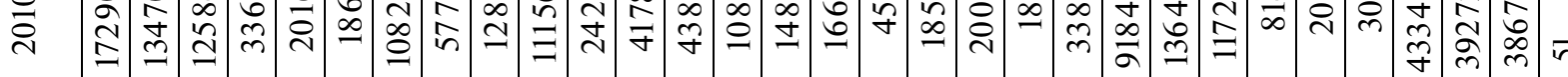

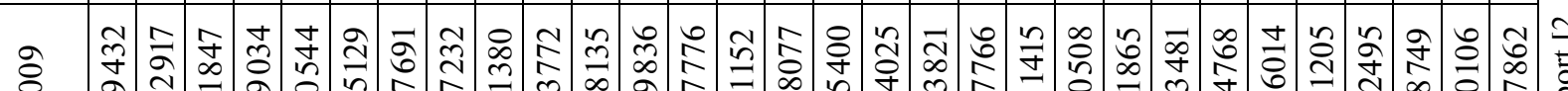

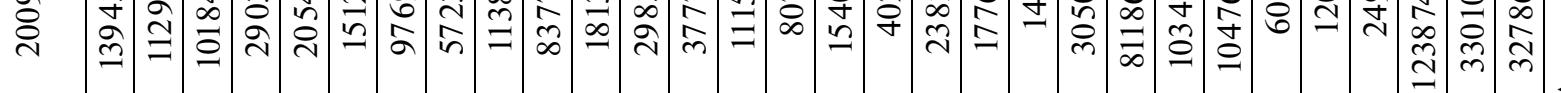

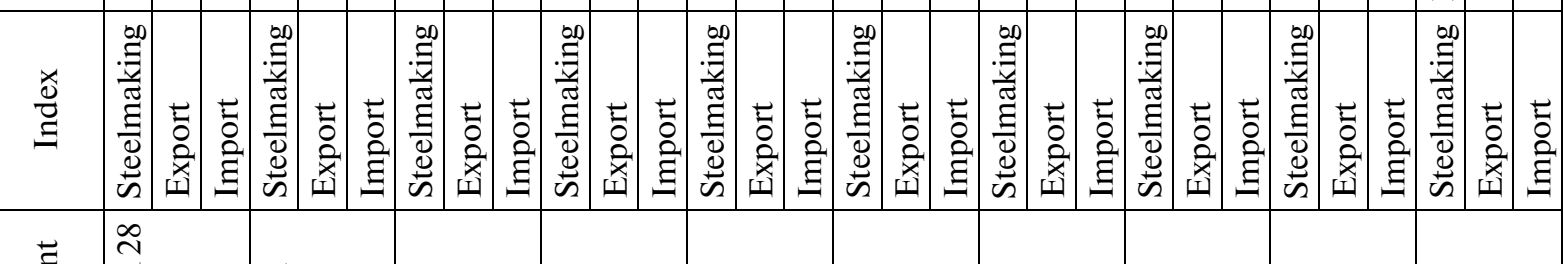
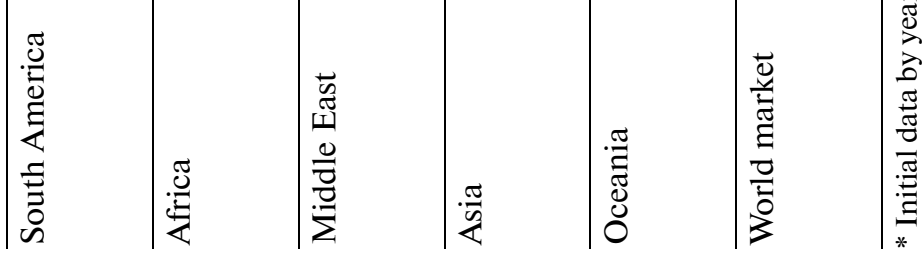

RUSSIAN METALLURGY (METALLY) Vol. $2021 \quad$ No. 6 

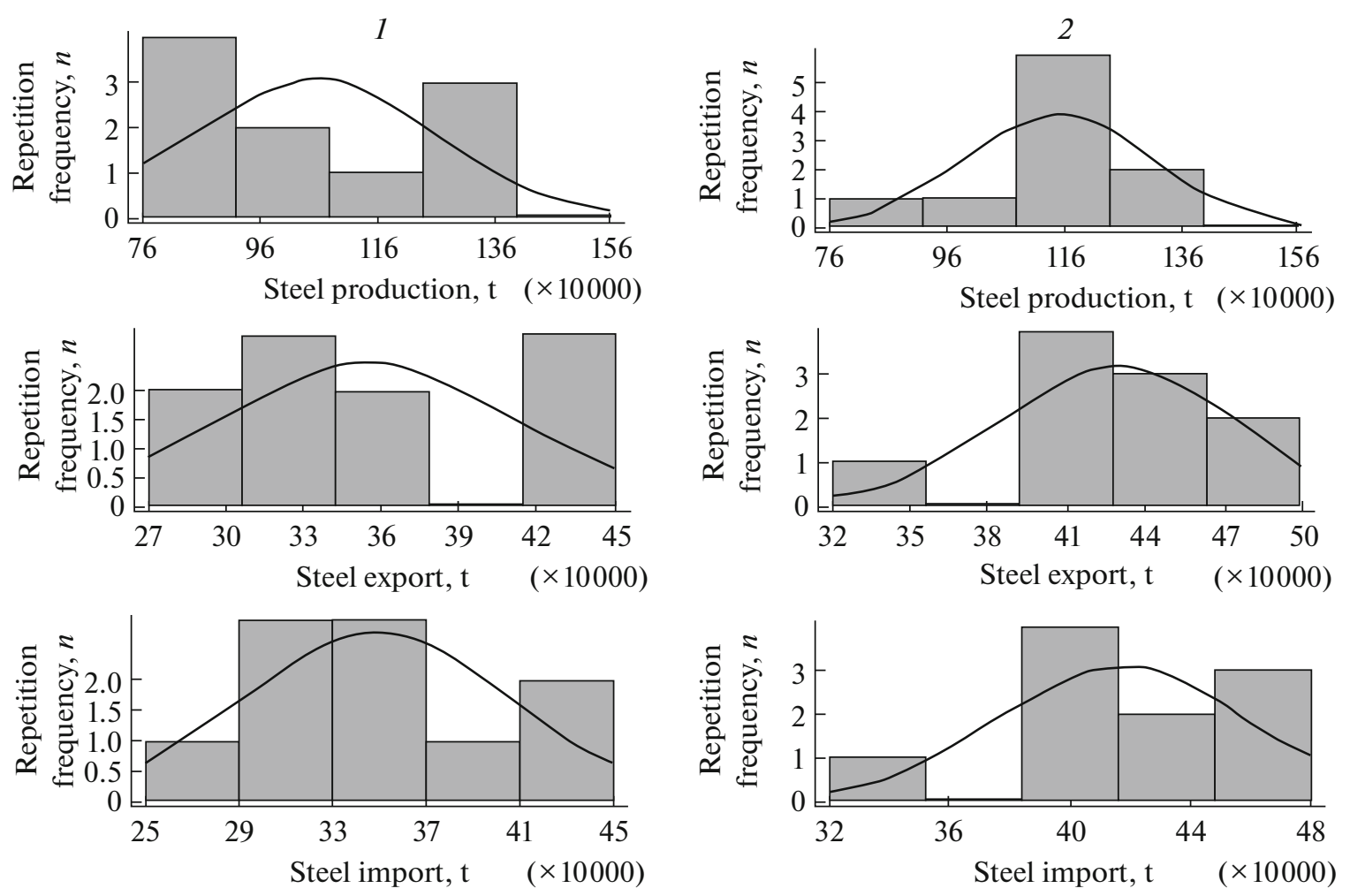

Fig. 2. Distribution of data on the world production, export, and import of steel in various periods at the turn of the 20th and the 21st centuries: (1) 1999-2008 and (2) 2009-2018.

The control action on this market was really being adjusted at governmental or intergovernmental level. It was actually impossible for single companies to exert a significant effect on the world market due to comparatively low production amounts in comparison with the world indices. Collective impact on the market conditions could be exposed only by Chinese metallurgical holdings from the Top 50 steel manufacturers [7]. Therefore, real manufacturers should reasonably take into account the situation in specific market segment, and then, maintaining balanced position in production and export/import business, actively perform the decisions made by the company management aimed at strengthening of positions in respective segment of the world market of goods and services.

The data [8] describe a close interrelation between the world indices of steelmaking and consumption and the results of export/import operations with steel products. With consideration for these results, this work estimates the strategies of efficiency of production development and export/import operations in the main segments of the world steel market. The analysis is based on the changes of indices characterizing production amounts of liquid steel in these segments and on the world market in 2009-2018 [6]. Competitive advantages of various variants of business activity were estimated using the generalized Hurwitz criterion $\left(G_{(P)}\right)$, which reflects the functions of efficiency of pure and possible mixed strategies of steel production, import, and export (in tons). The calculations are made according to the procedure described in [9] using the data of Table 1 and the reports $[5,6]$. The optimum strategy was determined by the highest index of the pure strategy $\left(G_{i}\right)$. The obtained results are shown in Fig. 3.

It follows from Fig. 3 that, in production sphere, the transfer of steel products in recent decade was at leading positions in comparison with export/import area of metal products in various segments of the world market except for Middle East, where import prevailed over production and export operations (see Fig. 3g). The strategy of manufacture development of wide range of products from steel and alloys at the world level most completely complied with the demands of the world economy in these main structural materials. During the previous decade the international commercial operations were a supplemental element of the market of goods and services upon satisfaction of the demand of buyers and consumers of metal products. In 2009-2018, as in the previous decade, the modern manufacturers nearly completely satisfied the market demands in steel products, which is evidenced by the data on the world steel production, apparent consumption and trends of their future development (Fig. 4). 

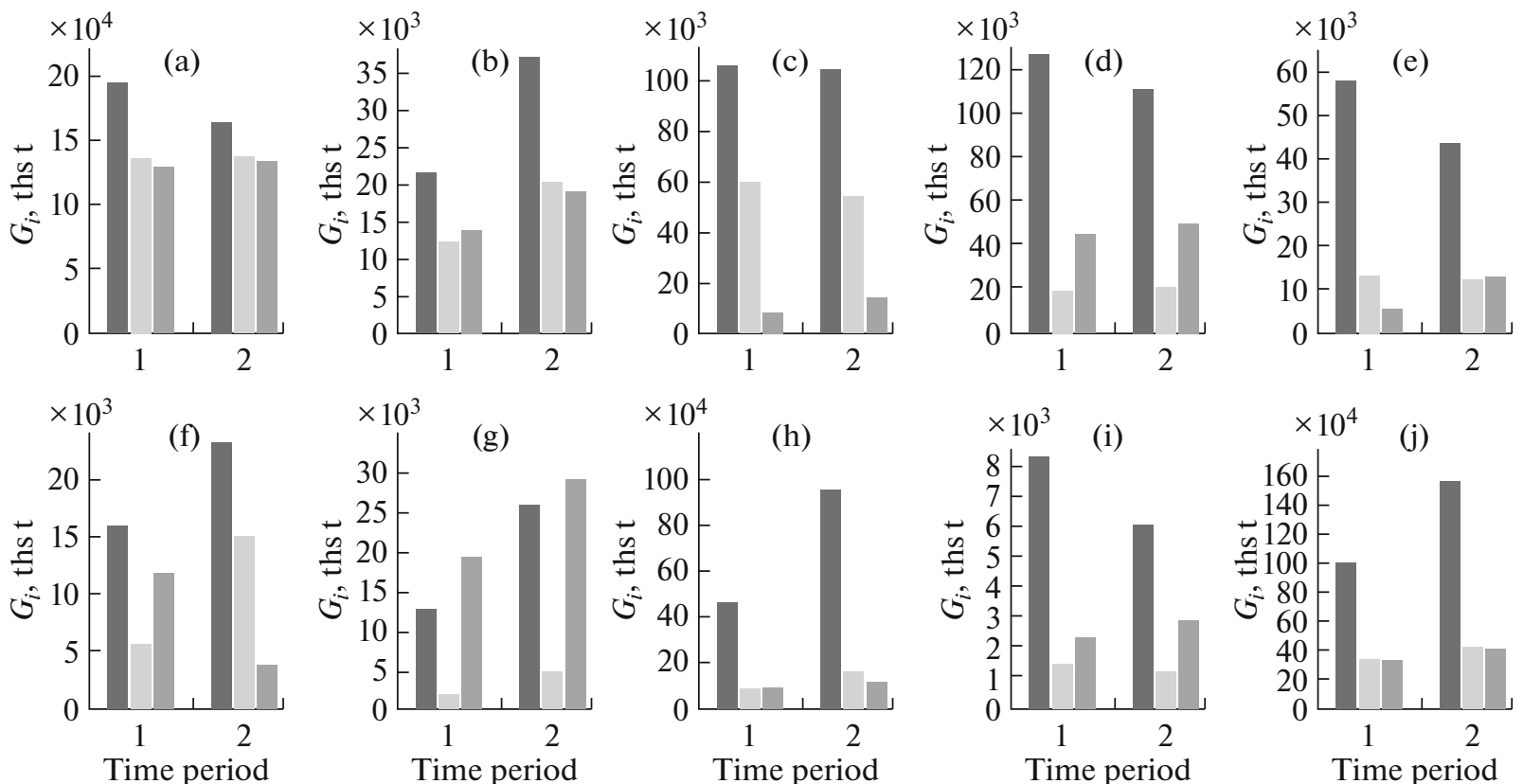

Fig. 3. Efficiency of the pure strategies of steel product transfer on the world market and its segments in (1) 1999-2008 and (2) 2009-2018: (a) European Union, (b) other European countries, (c) CIS, (d) North America, (e) South America, (f) Africa, (g) Middle East, (h) Asia, (i) Oceania, and (j) overall world. The columns from left to right, steelmaking and export and import of steel products.
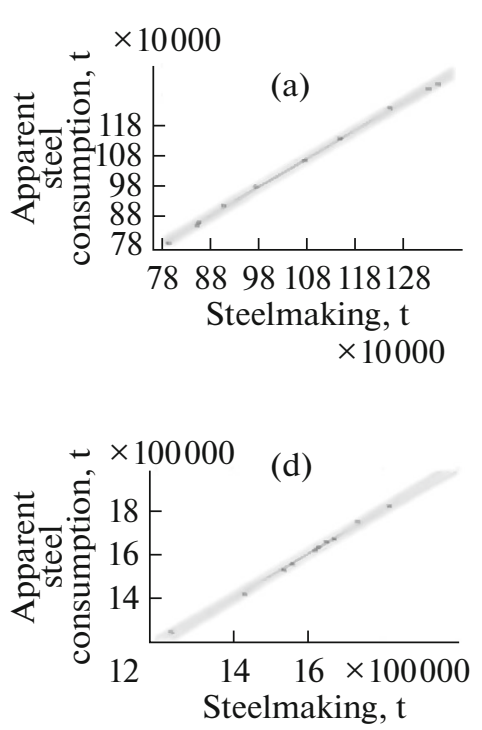
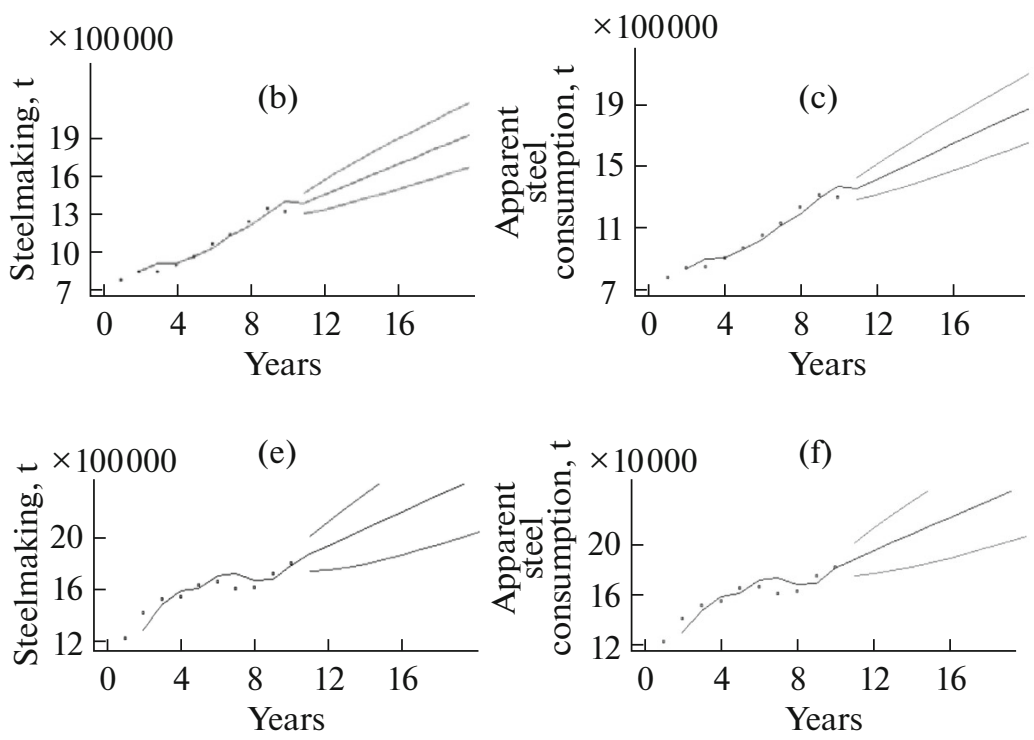

Fig. 4. World production and consumption of steel in (a-c) 1999-2008 and (d-f) 2009-2018: (a) $V_{\text {app.steel cons }}=42981+$ $0.951 V_{\text {melt.steel }}$ (coefficient of correlation is 0.999); (b) $V_{\text {melt.steel }}=679248+67391.8 t$; (c) $V_{\text {app.steel cons }}=687750+64347.9 t$ (reference point is 1999), $t$ is time, years; (d) $V_{\text {app.steel cons }}=-79057.8+1.052 V_{\text {melt.steel }}$ (coefficient of correlation 0.999); (e) $V_{\text {melt.steel }}=1324120+48189.6 t$; and (f) $V_{\text {app.steel cons }}=1309270+51439.4 t$ (reference point is 2009).

The efficiency of production and consumption of steel products is known to depend significantly on the conditions of balance between production and export/import operations on the market. The equilibrium of metal flow on the world market and its seg- ments was estimated by integral index of steel transfer $(K)$. This generalized index was calculated as average geometric value by the equitation $K=\sqrt[3]{k_{\mathrm{s}} k_{\mathrm{e}} k_{\mathrm{i}}}$, where $k_{\mathrm{s}}, k_{\mathrm{e}}, k_{\mathrm{i}}$ are coefficients equaling to the ratio of the average to maximum indices characterizing steelmak- 
(a)

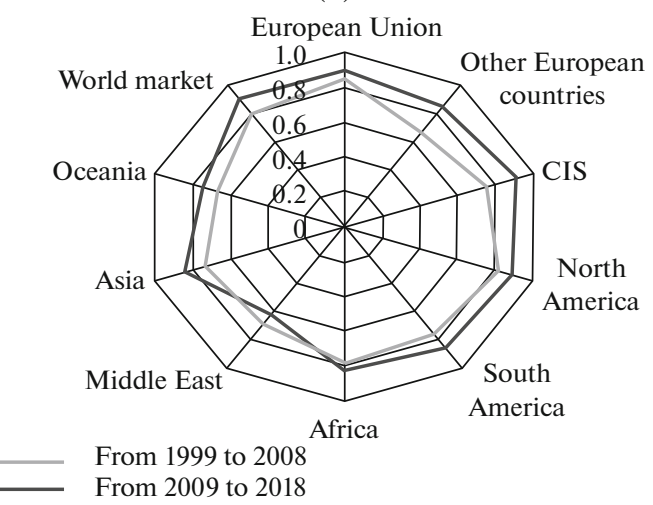

(b)

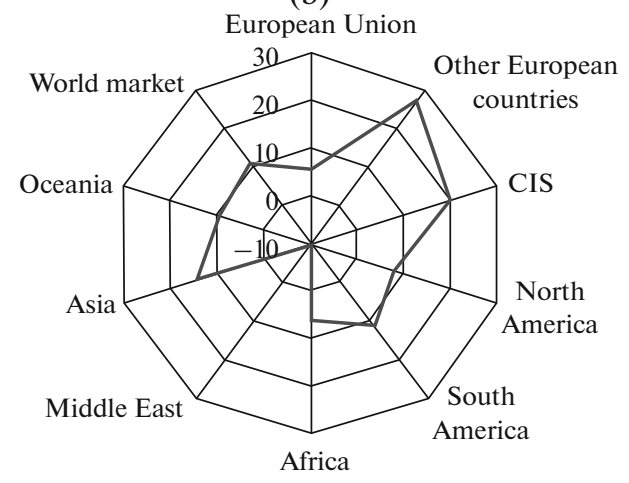

Fig. 5. Changes in the integral index of steel transfer on the world market and its segments before and after the 2008-2009 world crisis: (a) actual data, absolute value; (b) relative change, rel \%.

ing, export, and import, respectively. The initial and estimated results are summarized in Table 1 and Fig. 5.

During the time period of 1999-2018, a comparison of the integral indices of steel transfer in production and export/import business (Table 1, Fig. 5) revealed an increase in equilibrium of flow of steel products on the world market and most of its segments, except for Middle East. After the 2008-2009 world crisis, the integral index of steel transfer on the world market increased from 0.8056 to 0.8920 , i.e., by $10.7 \mathrm{rel} \%$. This is stipulated by the fact that in the main segments of manufacturers and active participants in foreign trading operations this coefficient was higher than 0.8 . The highest increase (up to $+27.3 \mathrm{rel} \%$ ) in the integral index of steel transfer was observed in the segment of other European countries, the highest decrease by -9.3 rel \% was in the segment of Middle East. The mentioned changes are stipulated mainly by high volatility of production and export/import indices before and after the 2008-2009 crisis, which accompanied the changes of their absolute values in the considered time periods. Therefore, the integral index of steel transfer, being a certain indicator of stabilization and changes of product flow on the world market and its segments, was used at rather illustrative estimation of dynamics in the strategic period of development of the steel market.

It should be mentioned that the obvious trend of increasing the production business in comparison with the foreign trade area was determined by the indices of Asian market segment. For such segments as European Union, CIS, North America, South America, and Oceania, the industrial trend was distinguished by a decrease in the index characterizing efficiency of pure strategies of transfer of steel products.

However, this trend did not exert negative impact on the total segment harmonicity of flow of steel products, which was characterized by high (higher than 0.8 ) integral index of steel transfer (see Fig. 5a). The change in export and import flows of steel in the men- tioned segments before and after the 2008-2009 crisis was, probably, determined not only by market factors but also by restrictive measures of impact on foreign trade operations by numerous countries, mainly USA and European Union. In recent decade the sharp decrease in the integral index of steel transfer in the segment of Middle East was influenced by political and military conflicts in this region. A combination of these factors influenced the steel transfer on the world market. Thus, it was possible to conclude that, upon an analysis of possibilities of development of market situation, it would be reasonable to pay peculiar attention to social and political factors, which can influence a market situation. This is especially important at present in the period of the so-called global turbulence characterized by sharp changes in energy prices, fall of stock indices, political confrontation between the leaders of states and alliances, as well as the coronavirus pandemic and respective reduction of business activity in various countries and development of measures of economy development under the new existing crisis situations $[10,11]$. The possibility of occurrence of new global economic crisis in 2020, initiated by the coronavirus pandemic, is an additional stimulating factor for rapid performance of studies devoted to selection and estimation of efficiency of development of competitive trends related with activation of business in production and foreign trade areas of business in the world steel market and its segments. The obtained results of this work are intended for solving the challenging problems in the filed of strategic planning and positive realization of partnership relations between the participants in the transactions on the world commodity market under modern conditions.

\section{REFERENCES}

1. Report by Malinetskii about the Potential of the Russian Federation (2009). http://www.nanonewsnet.ru/articles/2009/georgii-malinetskii-doklad-o-perspektivakh-rf. Cited March 5, 2020. 
2. World Steel in Figures 2019 (World Steel Association Brussels, Belgium, 2019). https://www.worldsteel.org/en/dam/jcr:96d7a585-e6b2-4d63-b943-4cd9ab62la 91/World\%2520Steel\%2520in\%2520Figures\%25202019.pdf. Cited March 5, 2020.

3. H. Haken. Information and Self-Organization: A Macroscopic Approach to Complex Systems (Springer, Berlin, 1988).

4. Worldsteel Association. Crude Steel Production, 1980-2014 https://ru.scribd.com/document/298016844/Steel-Annually-1980-2014. Cited March 5, 2020.

5. Steel Statistical Yearbook 2009. Worldsteel Committee on Economic Studies (Brussels, 2010). https://www.worldsteel.org/steel-by-topic/statistics.html. Cited March 5, 2020.

6. Steel Statistical Yearbook 2019. Concise Version. World Steel Association. Economics Committee (Brussels, 2019). https://www.worldsteel.org/steel-by-topic/statistics.html. Cited March 5, 2020.

7. Top Steelmakers in 2018 List of Companies with Tonnage of More Than 3 Million in 2018. https://www.worldsteel.org/en/dam/jcr:80ce948e-6a12-47d0-baf1-26799888

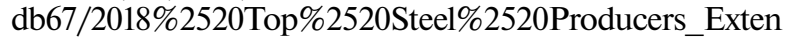
ded\%2520List.pdf. Cited March 5, 2020.
8. S. V. Bogdanov, I. Yu. Morozov, and T. V. Bogdanova, "The influence of production factors and export/import metal trading operations on the state of world steel market under modern conditions," Elektrometallurgiya, No. 3, 34-40 (2019).

9. S. V. Bogdanov and S. Yu. Nechaev, "Comparison of strategic competitive initiatives of Russian banking and metallurgical business in modern economic environment," Elektrometallurgiya, No. 12, 28-35 (2018).

10. "Mishustin requested to develop measures on development of economic under the coronavirus conditions," News. Russia. Economy. https://rueconomics.ru/ 433204-mishustin-poruchil-razrabotat-mery-po- razvitiyu-ekonomiki-v-svyazi-s-koronavirusom?utm_source $=$ yxnews\&utm_medium $=$ desktop\&utm_referrer $=$ https\% 3A\%2F\%2 Fyandex. ru\%2Fnews. Cited March 5, 2020.

11. Maslennikov, "Five minutes before ideal storm in world economy," Economy Today. World. Finances. https://rueconomics.ru/433182-maslennikov-do-idealnogo-shtorma-v-mirovoi-ekonomike-ostalos-pyat-minut. Cited March 5, 2020.

Translated by I. Moshkin 